\title{
The Cognitive Effects of Electroconvulsive Therapy in Community Settings
}

\author{
Harold A Sackeim**, ${ }^{*, 3}$, Joan Prudic ${ }^{1,2}$, Rice Fuller ${ }^{4}$, John Keilp ${ }^{2,5}$, Philip W Lavori ${ }^{6}$ and Mark Olfson ${ }^{2,7}$ \\ 'Department of Biological Psychiatry, New York State Psychiatric Institute, New York, NY, USA; '2Department of Psychiatry, College of Physicians \\ and Surgeons, Columbia University, New York, NY, USA; ${ }^{3}$ Department of Radiology, College of Physicians and Surgeons, Columbia University, New \\ York, NY, USA; ${ }^{4}$ Institute for Health, Health Care Policy, and Aging Research, Rutgers University, New Brunswick, NJ, USA; ${ }^{5}$ Department of \\ Neuroscience, New York State Psychiatric Institute, New York, NY, USA; ${ }^{6}$ Department of Veterans Affairs Cooperative Studies Program and the \\ Division of Biostatistics, Department of Health Research and Policy, Stanford University, Palo Alto, CA, USA; ${ }^{7}$ Department of Clinical and Genetic \\ Epidemiology, New York State Psychiatric Institute, New York, NY, USA
}

Despite ongoing controversy, there has never been a large-scale, prospective study of the cognitive effects of electroconvulsive therapy (ECT). We conducted a prospective, naturalistic, longitudinal study of clinical and cognitive outcomes in patients with major depression treated at seven facilities in the New York City metropolitan area. Of 751 patients referred for ECT with a provisional diagnosis of a depressive disorder, 347 patients were eligible and participated in at least one post-ECT outcome evaluation. The primary outcome measures, Modified Mini-Mental State exam scores, delayed recall scores from the Buschke Selective Reminding Test, and retrograde amnesia scores from the Columbia University Autobiographical Memory Interview-SF (AMI-SF), were evaluated shortly following the ECT course and 6 months later. A substantial number of secondary cognitive measures were also administered. The seven sites differed significantly in cognitive outcomes both immediately and 6 months following ECT, even when controlling for patient characteristics. Electrical waveform and electrode placement had marked cognitive effects. Sine wave stimulation resulted in pronounced slowing of reaction time, both immediately and 6 months following ECT. Bilateral (BL) ECT resulted in more severe and persisting retrograde amnesia than right unilateral ECT. Advancing age, lower premorbid intellectual function, and female gender were associated with greater cognitive deficits. Thus, adverse cognitive effects were detected 6 months following the acute treatment course. Cognitive outcomes varied across treatment facilities and differences in ECT technique largely accounted for these differences. Sine wave stimulation and BL electrode placement resulted in more severe and persistent deficits.

Neuropsychopharmacology (2007) 32, 244-254. doi: I 0. I038/sj.npp. I 30I I 80; published online 23 August 2006

Keywords: electroconvulsive therapy; major depression; memory; cognitive side effects; amnesia

\section{INTRODUCTION}

Electroconvulsive therapy (ECT) is widely considered the most effective antidepressant treatment, with medication resistance its leading indication (American Psychiatric Association, 2001). However, critics contend that ECT invariably results in substantial and permanent memory loss (Breggin, 1986; Sterling, 2000), with some patients experiencing a dense retrograde amnesia extending back several years (Donahue, 2000; Sackeim, 2000). In contrast, some authorities have argued that, with the introduction of general anesthesia and more efficient electrical waveforms,

* Correspondence: Dr HA Sackeim, Department of Biological Psychiatry, New York State Psychiatric Institute, 105 I Riverside Drive, New York, NY I0032, USA, Tel: + I 212543 5855, Fax: + I 212543 5854, E-mail: has I@columbia.edu

Received 9 March 2006; revised 17 May 2006; accepted 18 May 2006 Online publication: 12 July 2006 at http://www.acnp.org/citations/ Npp07| 206060 I57/default.pdf
ECT's adverse cognitive effects are short-lived, with no persistent effects on memory (Abrams, 2002; Fink, 2004).

Shortly following the ECT course, most patients manifest deficits in retaining newly learned information (anterograde amnesia) and recalling events that occurred in the weeks or months preceding the ECT course (retrograde amnesia) (Sackeim, 1992; Squire, 1986). Randomized-controlled trials have shown more severe short-term memory deficits with sine wave compared to brief pulse stimulation (Valentine et al, 1968; Weiner et al, 1986), bilateral (BL) compared to right unilateral (RUL) electrode placement (Lancaster et al, 1958; Sackeim et al, 1986; Sackeim et al, 1993; Sackeim et al, 2000), and higher electrical dosage (McCall et al, 2000; Ottosson, 1960; Sackeim et al, 1993). These adverse effects are reduced by the use of RUL ECT with brief or ultrabrief pulse stimulation and electrical dosage titrated to the needs of the individual patient (Sackeim, 2004b). Nonetheless, a minority of US practitioners still use sine wave stimulation, approximately half do not adjust dosage relative to the 
patient's seizure threshold, and a majority administer mainly or exclusively BL ECT (Farah and McCall, 1993; Prudic et al, 2004; Prudic et al, 2001). The continued use of treatment techniques associated with more severe short-term cognitive deficits may reflect the beliefs that the cognitive deficits are transient and that older treatment methods provide greater assurance of efficacy (Scott et al, 1992).

Empirical information about ECT's long-term effects derives mainly from small sample studies conducted in research settings, with follow-up intervals frequently limited to 2 months or less. By excluding individuals with significant medical and psychiatric comorbidities, use of optimized forms of ECT, and limited statistical power, these studies could not adequately assess the severity and persistence of long-term deficits. In a sample treated in community settings, we conducted the first large-scale, prospective long-term study of cognitive outcomes following ECT. We characterized the profile of cognitive change immediately and 6 months following completion of ECT, and examined the relationships of treatment technique and patient characteristics to cognitive outcomes. We also determined whether a patient subgroup had especially marked long-term deficits and whether particular forms of ECT administration were overrepresented among these patients.

\section{PATIENTS AND METHODS}

\section{Study Sites and Study Participation}

The study was conducted at seven hospitals in the New York City metropolitan area: two private psychiatric hospitals, three community general hospitals, and two hospitals at university medical centers. A clinical outcomes evaluator was assigned to each hospital and collected all research information. The study was conducted by investigators at the New York State Psychiatric Institute (NYSPI), and patients at this facility did not participate. Institutional Review Boards at NYSPI and each of the seven hospitals approved the study.

Participants were recruited from the in-patients and outpatients referred for ECT with a clinical diagnosis of a depressive disorder. Over a 26-month period, 751 patients were so referred (see Prudic et al (2004) and Figure 1 for details on sample composition). Study participants met the Diagnostic and Statistical Manual (DSM-IV) criteria for a major depressive episode (unipolar or bipolar) or schizoaffective disorder, depressed, on the basis of the Structured Clinical Interview for DSM-IV Axis I Disorders (SCID-I/P) (First et al, 1996a). Patients were excluded if they received ECT in the past 2 months, scored below 15 on the MiniMental State Exam (Folstein et al, 1975), or spoke neither English nor Spanish. Patients were at least 18 years of age

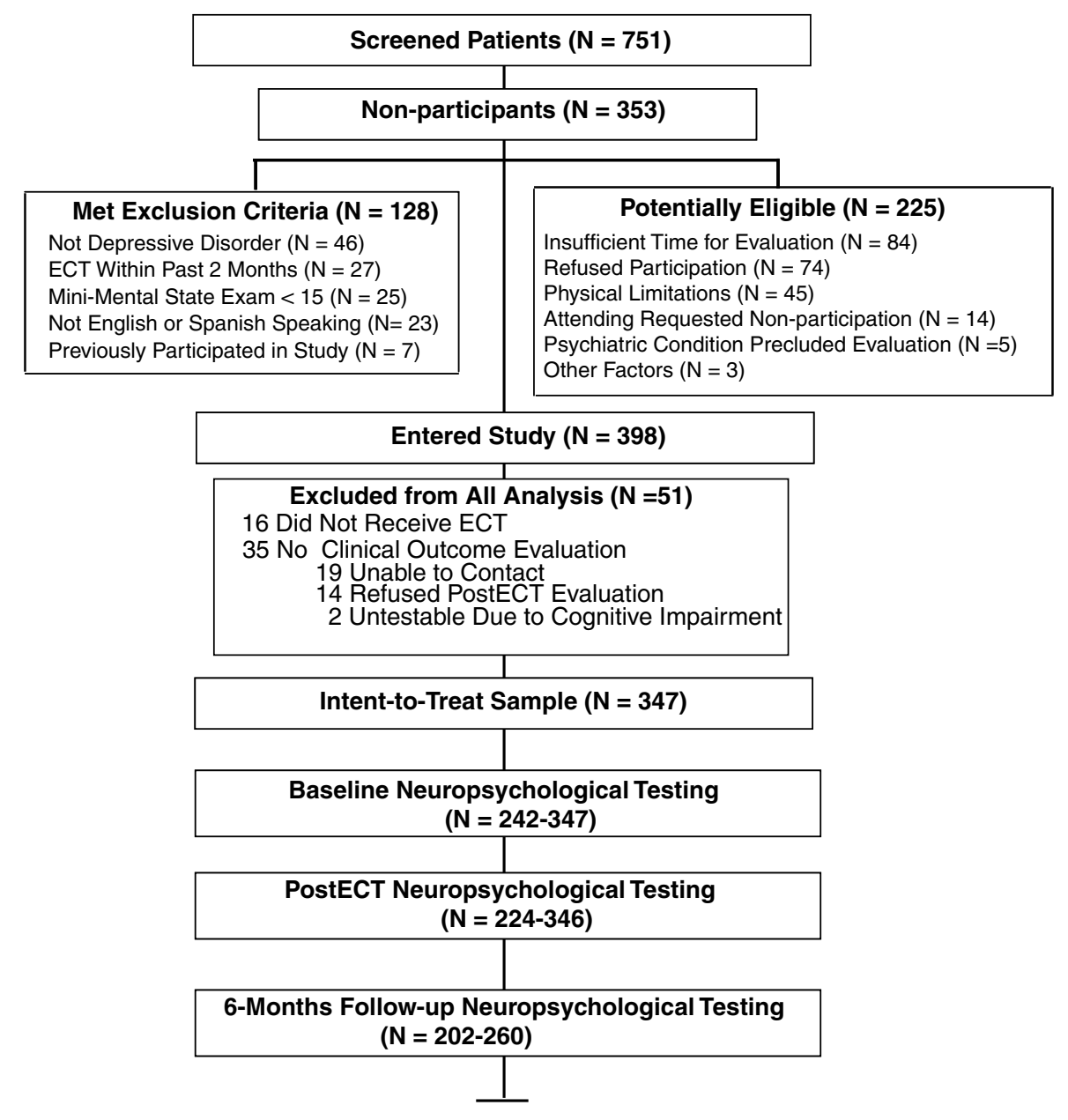

Figure I Participant flow. 
and provided informed consent after study procedures had been fully explained.

\section{Study Measures}

The primary instrument to assess severity of depressive symptoms was the Hamilton Rating Scale for Depression (HRSD, 24-item) (Hamilton, 1967). Comorbid DSM-IV psychiatric Axis I disorders, including substance abuse or dependence, were determined using a full SCID-I/P interview (First et al, 1996a). Medical comorbidity was assessed with the Cumulative Illness Rating Scale (CIRS) (Miller et al, 1992). At pre-ECT baseline, the North American Adult Reading Test (NAART) provided an estimate of premorbid intelligence (Johnstone et al, 1996).

An extensive neuropsychological battery was administered at pre-ECT baseline, within days of completing the ECT course, and at 6-month (24-week) follow-up. A description of the battery and the derived outcome measures are presented in Table 1. The modified MiniMental State exam (mMMS) (Stern et al, 1987), a measure of global cognitive status and an expanded version (range 057) of the original MMS (Folstein et al, 1975), has shown sensitivity to variation in ECT technique (Sackeim et al, 1993, 2000). Psychomotor function was assessed with three measures of reaction time (RT): Simple (SRT) (Benton, 1977), Choice (CRT) (Benton and Blackburn, 1957), and
Stroop RT (MacLeod, 1991). In each task, median RT for correct response was determined. Although psychomotor function is of practical importance with respect to driving and other motor activities, the impact of ECT on this domain has rarely been examined (Calev et al, 1995; Sackeim, 1992). Attention was assessed with the Stroop (MacLeod, 1991) and the Continuous Performance Test (CPT) (Ballard, 1997; Cornblatt et al, 1984). In severe depression, attention is often impaired, but believed to improve with symptomatic remission (Sternberg and Jarvik, 1976; Zakzanis et al, 1998). However, there is virtually no information on the effects of ECT on these classic attentional measures.

Anterograde and retrograde amnesia are the two deficits most characteristic of ECT. Anterograde learning and memory were assessed with the Complex Figure Test (CFT) (Rey, 1941; Spreen and Strauss, 1998) and the Buschke Selective Reminding Test (BSRT) (Buschke, 1973; Hannay and Levin, 1985). Deficits in delayed recall on the BSRT have been repeatedly documented shortly following ECT, and found to be sensitive to variation in the treatment technique (Sackeim et al, 1993; Sackeim et al, 2000). Retrograde amnesia for autobiographical information was measured with the Columbia University Autobiographical Memory Interview-Short Form (AMI-SF) (McElhiney et al, 1997, 1995). The original version of the AMI, containing 281 items, has shown strong reliability and validity as a measure

Table I Neuropsychological Battery

\begin{tabular}{|c|c|c|c|}
\hline Test & $\begin{array}{l}\text { Method of } \\
\text { administration }\end{array}$ & Outcome measure & $\begin{array}{l}\text { Task } \\
\text { order }\end{array}$ \\
\hline \multicolumn{4}{|l|}{ Global cognitive status } \\
\hline Modified Mini Mental State Exam (mMMS) & Paper-and-pencil & Total score $($ maximum $=57)$ & I \\
\hline \multicolumn{4}{|l|}{ Psychomotor function } \\
\hline Simple Reaction Time (SRT) & Computerized & Median reaction time on 60 trials & 4 \\
\hline Choice Reaction Time (CRT) & Computerized & $\begin{array}{l}\text { Median reaction time on correct trials (maximum } \\
\text { trials }=60 \text { ) }\end{array}$ & 5 \\
\hline Stroop Reaction Time (Stroop RT) & Computerized & $\begin{array}{l}\text { Median reaction time on correct trials on the Stroop } \\
\text { Test (maximum trials }=180 \text { ) }\end{array}$ & \\
\hline \multicolumn{4}{|l|}{ Attention } \\
\hline Stroop Color-Word Interference (Stroop effect) & Computerized & $\begin{array}{l}\text { Interference Score: Ratio of RT on color-word conflict } \\
\text { trials }(N=90) \text { to color trials }(N=45)\end{array}$ & 8 \\
\hline Continuous Performance Test (CPT) & Computerized & $\begin{array}{l}\text { Sensitivity }\left(d^{\prime}\right) \text { in detecting consecutive and identical } \\
\text { four digit targets (I } 50 \text { trials; } 28 \text { targets) }\end{array}$ & 6 \\
\hline \multicolumn{4}{|l|}{ Anterograde learning and memory } \\
\hline \multirow[t]{2}{*}{ Complex figure test (CFT) } & Paper-and-pencil & (I) Copying of complex figure & 3 \\
\hline & & $\begin{array}{l}\text { (2) Reproduction of complex figure after a } 20 \mathrm{~min} \\
\text { delay }\end{array}$ & 9 \\
\hline \multirow[t]{2}{*}{ Buschke Selective Reminding Test (BSRT) } & Paper-and-pencil & (I) Total recall of a list of 12 unrelated words on 6 trials & 2 \\
\hline & & (2) Free recall of the 12 words after a 30 min delay & 7 \\
\hline \multicolumn{4}{|l|}{ Autobiographical memory } \\
\hline $\begin{array}{l}\text { Autobiographical Memory Interview-Short Form } \\
\text { (AMI-SF) }\end{array}$ & Paper-and-pencil & $\begin{array}{l}\text { Consistency of report with baseline answers for } 30 \\
\text { questions about } 5 \text { autobiographical events }\end{array}$ & 10 \\
\hline
\end{tabular}


of retrograde amnesia, and sensitivity to variation in ECT technique (Lisanby et al, 2000; McElhiney et al, 1995; Sackeim et al, 1993, 2000; Sobin et al, 1995).

Three alternate versions of the mMMS, CFT, and BSRT were randomized to testing occasion. The order of the stimuli in each of the computerized tasks was newly randomized at each testing occasion. To allow for comparison of scores across tests and time points, the baseline scores on each test were converted to standardized scores, with a mean of $0(\mathrm{SD}=1)$ for the total sample. Scores at the two subsequent assessments were standardized in relation to the distribution of scores at baseline. In all cases, higher standardized scores reflected superior performance.

The primary cognitive outcome measures were post-ECT scores on the AMI-SF, mMMS, and delayed recall on the BSRT. The primary measure at the 6-month follow-up was the AMI-SF score. To identify a subgroup with marked and persistent retrograde amnesia, the most common source of complaint regarding long-term deficits, individuals were identified who following both the post-ECT and 6-month follow-up assessments had decreases of at least $-2.0 \mathrm{SD}$ units or greater on the AMI-SF.

\section{Study Procedures}

The outcomes evaluators screened all patients scheduled to start ECT at the facility with a provisional clinical diagnosis of a depressive disorder $(N=751$; Figure 1$)$. After obtaining consent and determining eligibility, the evaluator administered the clinical assessment and neuropsychological batteries before the first ECT treatment $(N=398)$. The intent-to-treat sample included those patients who received at least one treatment and participated in a post-ECT clinical outcome evaluation $(N=347)$. Time limitations and other factors resulted in variable rates of completion of the cognitive tasks, especially at the baseline evaluation. For the baseline assessment, the sample size for the cognitive measures ranged from 242 (CPT) to 347 (mMMS). The ranges were 224-346 and 202-260 at the post-ECT and 6-month follow-ups. Thus, $99 \%$ of the intent-to-treat sample participated in all or part of the cognitive evaluation at post-ECT and $75 \%$ did so at the 6-month follow-up.

The outcomes evaluator attended ECT treatments and documented the type and doses of medications, type of physiological monitoring, ECT device model, electrical waveform, electrode placement, stimulus dosing strategy, and the specific parameters used for stimulation. The duration of the motor convulsion and, when monitored, the EEG seizure were recorded.

When the treating psychiatrist indicated that the acute ECT course was completed, the patient was scheduled for the post-ECT assessment. The aim was to test patients between 3 and 7 days after ECT. For the 347 patients in the intent-to-treat sample, the average interval to post-ECT assessment was 4.37 days $(\mathrm{SD}=4.19)$. At the post-ECT assessment, the Structured Clinical Interview for DSM-IV Axis II Personality Disorders (SCID-II) was administered to derive DSM-IV diagnoses of personality disorders (First et al, 1996b). All consenting patients were clinically monitored for a period of 24 weeks following the acute ECT course. They were administered the HRSD at 4-week intervals and interviewed regarding the treatments received since last contact. At the 6-month time point, the clinical and neuropsychological evaluations were repeated.

A group of 24 healthy comparison participants, with negative lifetime histories of psychiatric illness, were matched to the patient sample in the distributions of age, gender, and education. The comparison sample completed the same neuropsychological battery at time points corresponding to the assessment periods in patients and each test was scored in standardized units relative to the patient distribution at baseline. Only one measure, $d^{\prime}$ or sensitivity on the CPT, showed a practice effect, with significant improvement from baseline to the post-ECT time point and stable thereafter. The scoring of the AMI-SF necessarily results in higher scores at baseline than followup. The CPT and AMI-SF scores in the patient sample were adjusted for the average change seen in the comparison sample, removing the temporal effects on these two measures.

Average raw scores for the patient sample and average raw and standardized scores for the healthy comparison sample are presented for the baseline evaluation in Table 2. Analyses of covariance (ANCOVAs), with age, gender, and

Table 2 Clinical and Demographic Characteristics of the Intent-to-Treat Sample $(N=347)$

\begin{tabular}{lc}
\hline Continuous variable & \\
Age, mean (SD) (years) & $56.7(17.6)$ \\
Education, mean (SD) (years) & $13.9(3.2)$ \\
Estimated verbal IQ, mean (SD) & $103.0($ I2.1) \\
Hamilton Rating Scale for Depression, mean (SD) & $31.3(6.9)$ \\
Beck Depression Inventory, mean (SD) & $35.4($ II.7) \\
Global Assessment Scale, mean (SD) & $31.0(9.2)$ \\
Cumulative medical burden, mean (SD) & $2.7(2.3)$ \\
Episode duration, median (week) & 24.0 \\
No. of medication trials during episode, mean (SD) & $4.7(2.9)$ \\
No. of adequate medication trials during episode, mean (SD) & $1.2(1.3)$ \\
Age at onset, mean (SD) (years) & $36.3(19.4)$ \\
No. of previous episodes, mean (SD) & $2.7(3.3)$ \\
No. of previous psychiatric hospitalizations, mean (SD) & $1.8(1.6)$ \\
& \\
Categorical variable & \\
Women (\%) & 63.1 \\
Race, White (\%) & 85.9 \\
Mood disorder diagnostic subtype & \\
Unipolar nonpsychotic (\%) & 59.9 \\
Unipolar psychotic (\%) & 20.5 \\
Bipolar nonpsychotic (\%) & 11.8 \\
Bipolar psychotic (\%) & 3.8 \\
Schizoaffective (\%) & 4.0 \\
Axis I (\%) & \\
Axis 2 (\%) & 42.1 \\
In-patient (\%) & 64.6 \\
Medication resistant (\%) & 43.5 \\
\hline & \\
\hline & \\
\hline
\end{tabular}


education as covariates indicated that the healthy comparison sample had superior scores on nine of 11 of the baseline cognitive measures.

\section{Statistical Methods}

The pattern of change in neuropsychological scores was determined for the total sample by conducting paired $t$-tests contrasting scores at post-ECT and 6-month follow-up with pre-ECT scores. Differences among the sites in cognitive outcomes were tested with ANCOVAs. For each measure, an ANCOVA was conducted on the score at post-ECT with site (seven levels) as a between-subject term and patient age, estimated premorbid IQ (based on the NAART), gender, HRSD score at time of assessment, number of days intervening between the end of ECT and post-ECT assessment, and pre-ECT baseline cognitive score as covariates. The ANCOVAs conducted on the neuropsychological measures at the 6-month follow-up used the same model except that the number days since end of ECT was dropped and whether or not patients had received further treatment with ECT in the follow-up period was added as a covariate. The covariates in these models were selected $a$ priori based upon reported associations with post-ECT cognitive measures (Sackeim et al, 1992; Sobin et al, 1995; Zervas et al, 1993). Other potential covariates screened for inclusion in the analyses were cumulative medical burden (CIRS score), other Axis I diagnosis, Axis II diagnosis, psychotic depression subtype, in-patient $v s$ outpatient treatment setting, history of previous ECT, length of current depressive episode, and number of previous depressive episodes. The criterion for inclusion of a covariate in the final analyses was a significant association $(p<0.05)$ with at least two of the primary outcome measures. None of the screened variables met this criterion. Post hoc Tukey-Kramer comparisons identified pair-wise differences among the sites.

The associations between treatment technique and cognitive outcomes were first tested in the subgroup of patients who were treated with only one electrode placement, BL or RUL ECT, during acute-phase treatment. Patients treated exclusively with bifrontal (BF) ECT $(n=12)$, a mixture of BL, RUL, and/or BF ECT $(n=75)$, or exclusively with RUL ECT with sine wave stimulation $(n=2)$ were dropped from these analyses. The ANCOVAs used the same models as the analyses of site differences, except that the site term was deleted and terms for electrode placement, waveform nested within electrode placement, stimulus dosage, and number of treatments were added. Stimulus dosage was computed as the percentage of maximal device output averaged across all treatments. To corroborate findings, a second set of ANCOVAs was conducted in the intent-to-treat sample. In these analyses, the terms for the number of $\mathrm{BF}, \mathrm{BL}$, and RUL treatments (three factors) replaced the categorical classification of electrode placement and the term for the total number of treatments. To determine whether the site differences were attributable to differences in treatment technique, the last set of analyses was repeated adding site as a between-subject factor. A logistic regression analysis was conducted to determine which treatment technique factors were related to likelihood of manifesting especially marked and persistent retrograde amnesia.

\section{RESULTS}

Compared to baseline performance, at the post-ECT time point the total patient sample showed deficits in the mMMS $(t(345)=8.0, p<0.0001)$, SRT $(t(281)=4.2, p<0.0001)$, sensitivity $\left(d^{\prime}\right)$ on the CPT $(t(221)=7.4, \quad p<0.0001)$, learning phase of the BSRT $(t(314)=3.5, p<0.0001)$, delayed recall on the BSRT $(t(301)=10.5, p<0.0001)$, delayed reproduction on the CFT $(t(270)=7.2, p<0.0001)$, and in AMI-SF scores $(t(328)=21.7, p<0.0001)$ (Figure 2). At this time point, the Stroop interference effect was reduced $(t(264)=5.3, p<0.0001)$. The deficits following ECT were greatest for the measures assessing memory for autobiographical events (AMI-SF), retention of newly learned information (delayed performance on the BSRT and CFT), global cognitive status (mMMS), and simple reaction time (SRT). Compared to the pre-ECT baseline, there was significantly improved performance at the 6month follow-up on all tasks other than the three RT measures (SRT, CRT, and Stroop RT) and sensitivity $\left(d^{\prime}\right)$ on the CPT. Furthermore, AMI-SF scores remained markedly below baseline values $(t(251)=21.1, p<0.0001)$.

There were no significant differences among the seven hospitals in ANCOVAs conducted on the pre-ECT baseline cognitive measures. In contrast, the seven hospitals differed in mMMS and AMI-SF scores at both the post-ECT (mMMS: $F(6,333)=3.25, \quad p=0.004 ; \quad$ AMI-SF: $\quad F(6,313)=2.70$, $p=0.01)$ and 6-month follow-up (mMMS: $F(6,248)=3.43$, $p=0.003$; AMI-SF: $F(6,240)=2.26, p=0.04)$ time points (Figure 3). In addition, there were significant differences among the hospitals at the post-ECT assessment for five other cognitive measures: CRT $(F(6,244)=3.34, p=0.004)$, Stroop RT $(F(6,252)=3.02, p=0.007)$, CPT sensitivity $\left(d^{\prime}\right)$ $(F(6,211)=2.23, p=0.04)$, BSRT learning $(F(6,302)=2.14$, $p<0.05)$, and BSRT delayed recall $(F(6,289)=2.19$, $p=0.04)$. Across these seven measures and time points, patients at hospital D consistently showed marked deficits, whereas patients at hospital G showed the least impairment. The site differences in short- and long-term cognitive outcomes persisted following statistical control for the

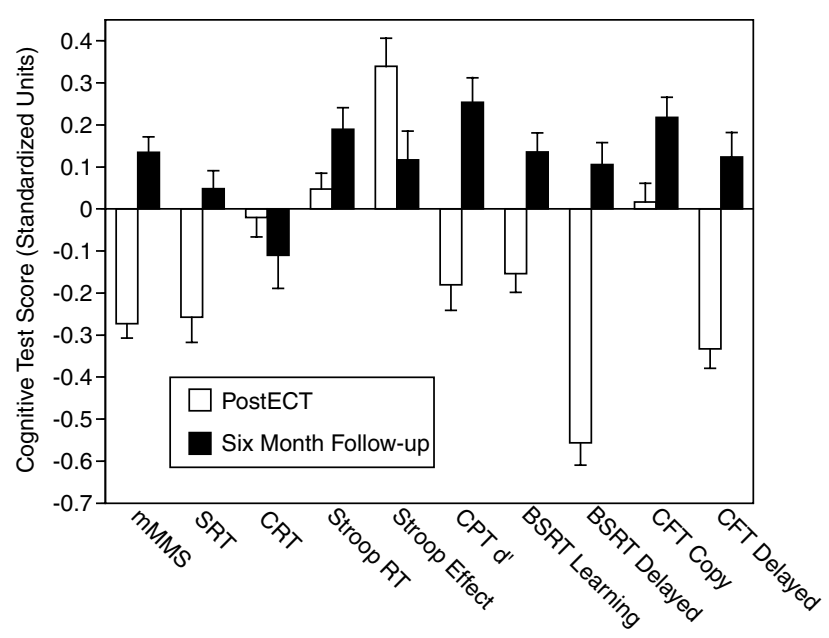

Figure 2 Scores on II cognitive measures immediately following and 6 months after a course of ECT. Scores for each test, other than the AMI-SF were standardized relative to the distribution of scores at baseline. 

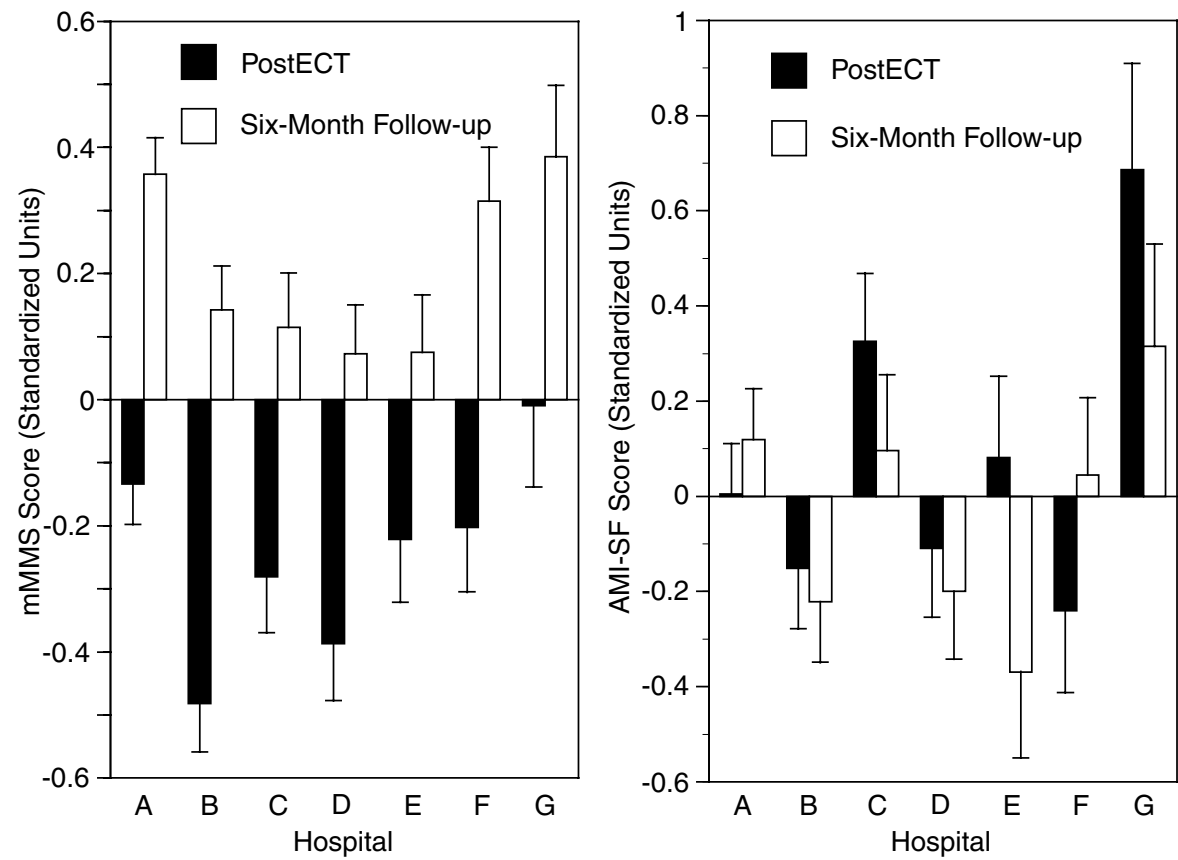

Figure 3 Scores on the modified Mini-Mental State Exam (mMMS) and the Columbia University Autobiographical Memory Interview: Short Form (AMI-SF) immediately and 6 months following ECT at each of the seven sites.

Table 3 Baseline Cognitive Test Scores for the Depressed and Healthy Comparison Samples

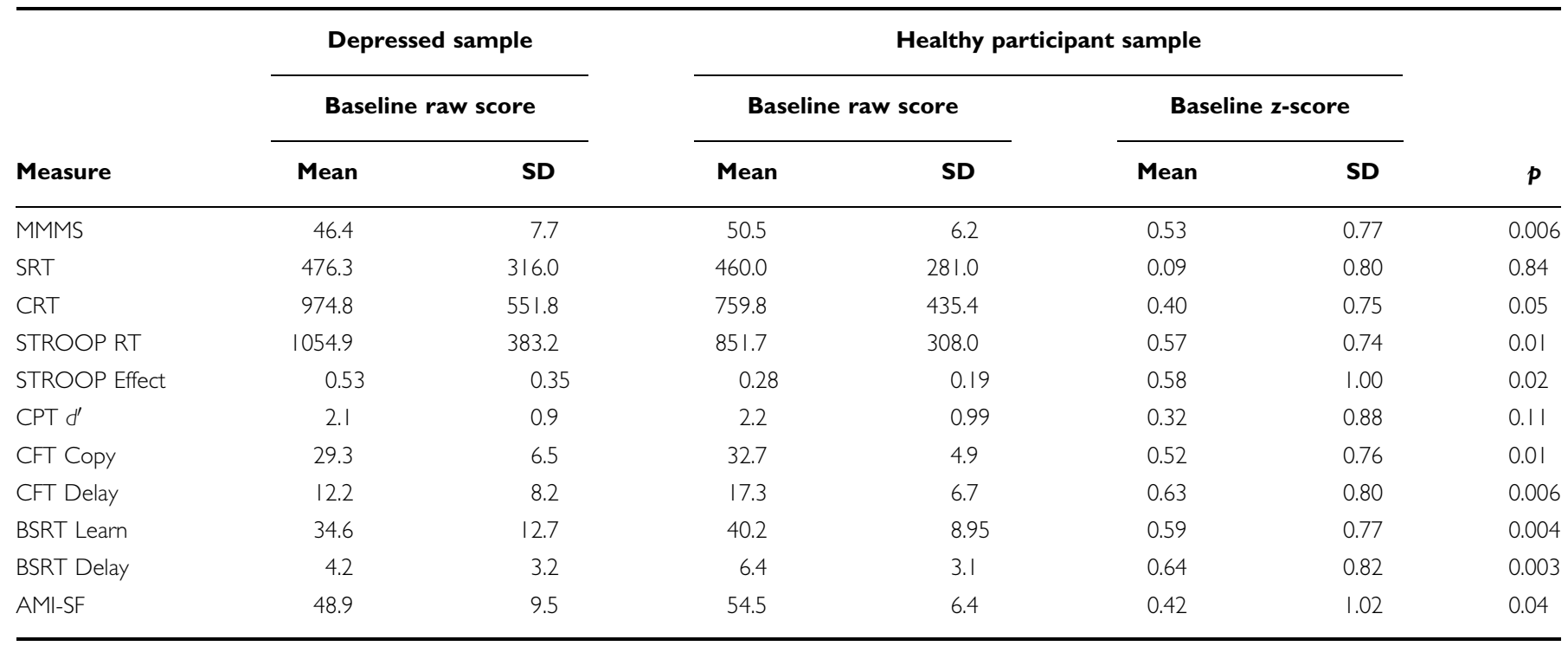

The $p$-value is from the main effect of diagnostic group (depressed vs comparison sample) in the ANCOVA on each standardized test score, with age, gender, and grade level as covariates.

patient features most strongly associated with the cognitive measures.

When the sample was restricted to patients treated with a uniform electrode placement $(N=258)$, there were marked effects of specific aspects of ECT practice on short- and long-term cognitive measures. At post-ECT, stimulus waveform had a significant impact on four of the 11 cognitive measures (Table 3, Figure 4). In each case, performance was poorer with sine wave compared to brief pulse stimulation. There were robust effects of sine wave stimulation on all three RT measures. At post-ECT, patients treated with BL or RUL ECT differed significantly in five of the 11 cognitive measures (Table 3, Figure 4). BL ECT was associated with greater amnesia than RUL ECT on two of the three primary outcome measures, delayed recall on the BSRT and memory for autobiographical events (AMI-SF). The effects of electrode placement and number of ECT treatments were especially marked on the AMI-SF (Figure 5).

At the 6-month follow-up, patients treated with sine wave stimulation continued to have slower RT on the SRT and the Stroop RT tasks (Table 4, Figure 4). At this time point, patients treated with BL ECT had inferior performance to patients treated with RUL ECT on the mMMS, 


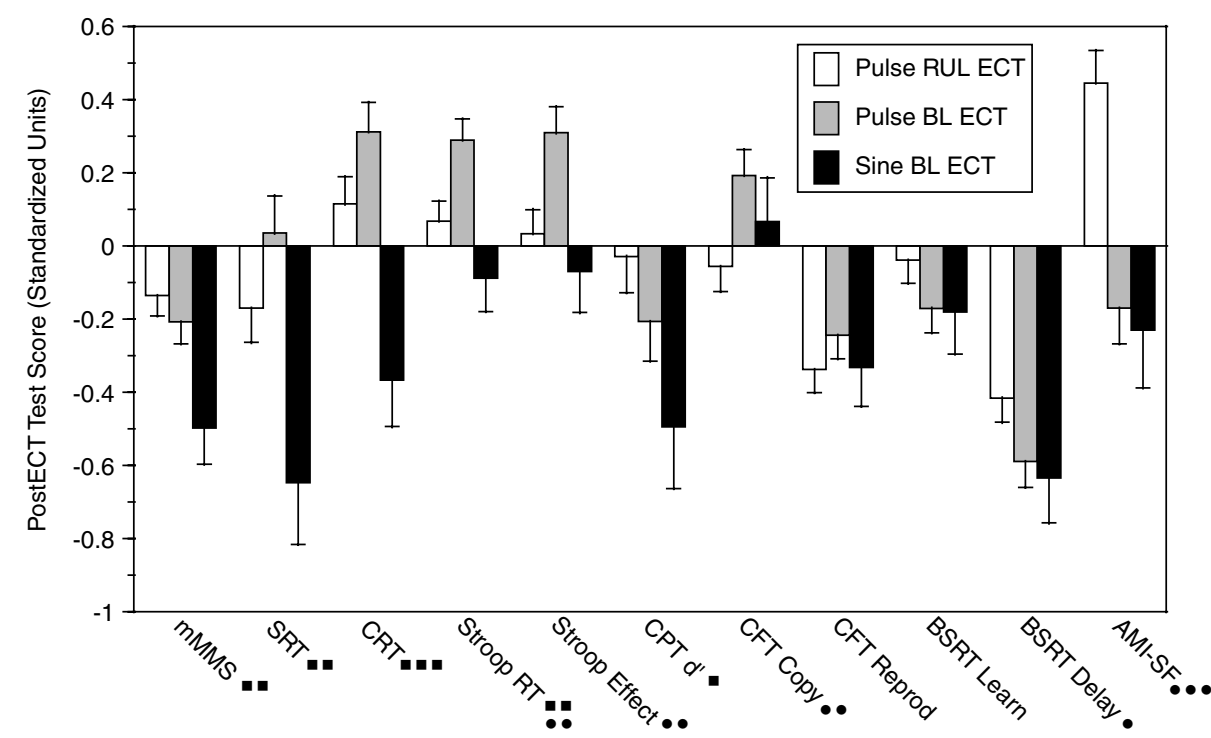

Figure 4 Scores on the I I cognitive measures immediately following the ECT course for patients treated with brief pulse right unilateral (RUL). ECT, brief pulse bilateral $(\mathrm{BL})$. ECT, and sine wave BL ECT. Filled boxes indicate a significant effect of waveform in the ANCOVA $(\mathbf{\square}=p<0.05 ; \mathbf{\square}=p<0.01$; 口 $=p<0.00 \mathrm{I})$. Filled circles indicate a significant effect of electrode placement in the ANCOVA $(\mathbf{O}=p<0.05$; $\boldsymbol{0}=p<0.0 \mathrm{O}$; $00<0.001)$.

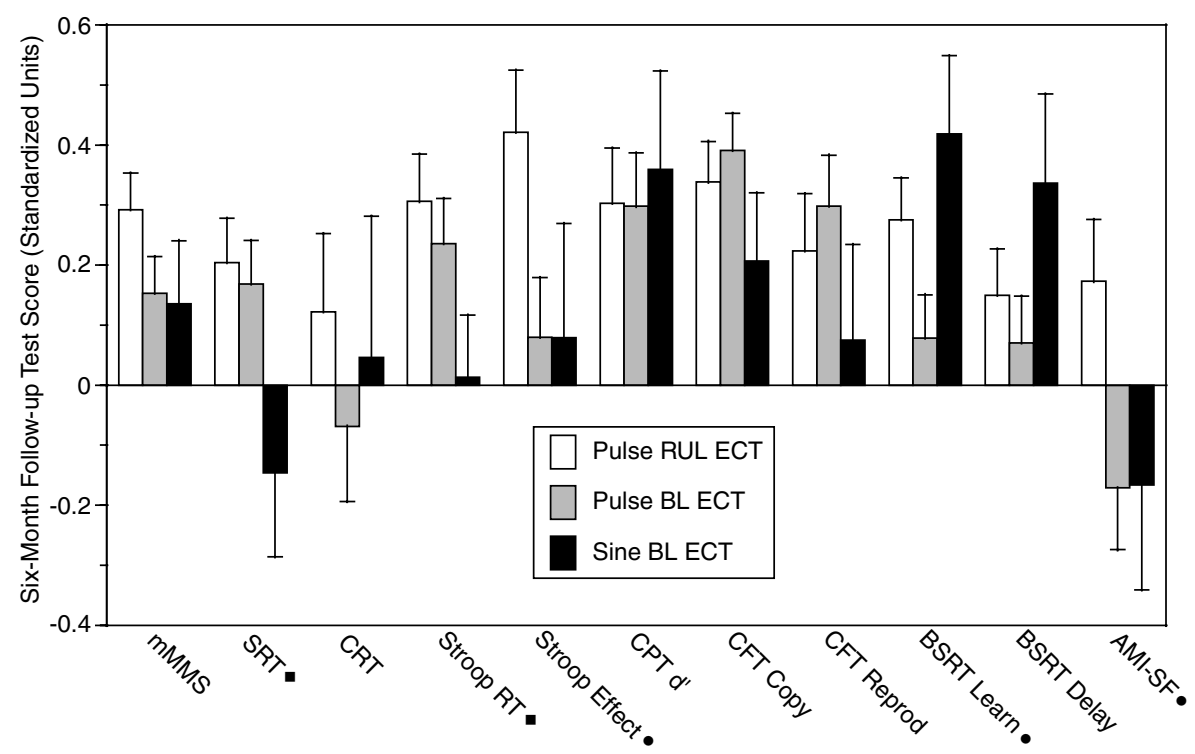

Figure 5 Scores on the II cognitive measures 6 months following the ECT course for patients treated with brief pulse right unilateral (RUL). ECT, brief pulse bilateral (BL). ECT, and sine wave BL ECT. Filled boxes indicate a significant effect of waveform in the ANCOVA $(\boldsymbol{\square}=p<0.05)$. Filled circles indicate a significant effect of electrode placement in the ANCOVA $(\mathbf{O}=p<0.05)$.

SRT, Stroop effect, learning phase of the BSRT, and AMI-SF scores. Greater amnesia for autobiographical events (AMISF scores) was significantly correlated with the number of ECT treatments received 6-months earlier (Table 5).

In the confirmatory analyses, there were significant linear relationships between the number of treatments administered and post-ECT AMI-SF scores for each of the three electrode placements. However, the slope of the decline in AMI-SF scores with increasing treatment number was substantially greater for BL ECT $(F(1,318)=$ 53.74, slope $=-0.14, \quad \mathrm{SE}=0.02, \quad p<0.0001) \quad$ than RUL $(F(1,318)=7.72$, slope $=-0.06, \quad \mathrm{SE}=0.02 ; p=0.005)$ or bifrontal ECT $(F(1,318)=8.01$, slope $=-0.09, \mathrm{SE}=0.03$, $p=0.005)$. At the 6 -month time point, there continued to be a significant relationship between the number of $\mathrm{BL}$ ECT treatments and the extent of retrograde amnesia $(F(1,240)=9.61, \quad \mathrm{df}=1, \quad 240, \quad$ slope $=-0.06, \quad \mathrm{SE}=0.02$, $p=0.002$ ), whereas there were no relationships with the RUL or BF placements. Thus, the magnitude of long-term retrograde amnesia linearly increased with longer courses of BL ECT, but was unrelated to the number of RUL or BF treatments administered.

Of the 306 patients classified, $38(12.4 \%)$ patients met the a priori criteria for having marked and persistent retrograde 
Table 4 Results of the ANCOVAs on Neuropsychological Scores Shortly Following the ECT Course

\begin{tabular}{|c|c|c|c|c|c|c|c|c|c|c|c|c|c|c|c|c|c|c|c|c|c|c|}
\hline \multirow[b]{2}{*}{ Variable } & \multicolumn{2}{|c|}{$\begin{array}{l}\text { MMMS } \\
N=257\end{array}$} & \multicolumn{2}{|c|}{$\begin{array}{c}\text { SRT } \\
N=21 \text { I }\end{array}$} & \multicolumn{2}{|c|}{$\begin{array}{c}\text { CRT } \\
N=227\end{array}$} & \multicolumn{2}{|c|}{$\begin{array}{c}\text { Stroop RT } \\
N=199\end{array}$} & \multicolumn{2}{|c|}{$\begin{array}{l}\text { Stroop effect } \\
\quad N=199\end{array}$} & \multicolumn{2}{|c|}{$\begin{array}{l}\text { CPT d } \\
N=167\end{array}$} & \multicolumn{2}{|c|}{$\begin{array}{c}\text { CFT copy } \\
N=218\end{array}$} & \multicolumn{2}{|c|}{$\begin{array}{c}\text { CFT reproduction } \\
\qquad N=203\end{array}$} & \multicolumn{2}{|c|}{$\begin{array}{c}\text { BSRT learn } \\
N=236\end{array}$} & \multicolumn{2}{|c|}{$\begin{array}{l}\text { BSRT delay } \\
\qquad N=225\end{array}$} & \multicolumn{2}{|c|}{$\begin{array}{l}\text { AMI-SF } \\
N=243\end{array}$} \\
\hline & $\boldsymbol{F}$ & $p$ & $\boldsymbol{F}$ & $p$ & $F$ & $p$ & $\boldsymbol{F}$ & $p$ & $\boldsymbol{F}$ & $p$ & $\boldsymbol{F}$ & $p$ & $F$ & $p$ & $\boldsymbol{F}$ & $p$ & $\boldsymbol{F}$ & $p$ & $\boldsymbol{F}$ & $p$ & $\boldsymbol{F}$ & $p$ \\
\hline Waveform & 6.89 & 0.009 & 11.81 & 0.0007 & 13.74 & 0.0003 & 14.33 & 0.0002 & 0.37 & 0.54 & 1.82 & 0.18 & 0.00 & 0.99 & 0.50 & 0.48 & 0.01 & 0.94 & 0.10 & 0.75 & 0.56 & 0.46 \\
\hline $\begin{array}{l}\text { Electrode } \\
\text { placement }\end{array}$ & 0.71 & 0.40 & 2.32 & 0.13 & 3.17 & 0.08 & 8.83 & 0.003 & 0.62 & 0.43 & 1.80 & 0.18 & 6.78 & 0.009 & 1.07 & 0.30 & 4.10 & 0.04 & 4.15 & 0.04 & 20.23 & $<0.000$ I \\
\hline Electrical dosage & 1.42 & 0.23 & 0.59 & 0.44 & 0.95 & 0.33 & 0.63 & 0.43 & 0.01 & 0.90 & 0.00 & 0.98 & 0.76 & 0.38 & 0.11 & 0.74 & 0.30 & 0.58 & 0.14 & 0.71 & 0.28 & 0.60 \\
\hline $\begin{array}{l}\text { Number of } \\
\text { treatments }\end{array}$ & 0.78 & 0.38 & 0.00 & 0.97 & 0.06 & 0.81 & 0.00 & 0.96 & 0.61 & 0.44 & 0.71 & 0.40 & 3.12 & 0.08 & 1.01 & 0.32 & 0.58 & 0.45 & 0.90 & 0.35 & 33.56 & $<0.0001$ \\
\hline Age (years) & 8.07 & 0.005 & 16.08 & $<0.0001$ & 24.91 & $<0.0001$ & 46.67 & $<\mathbf{0 . 0 0 0 1}$ & 4.68 & 0.03 & 11.63 & 0.0008 & 6.06 & 0.01 & 2.54 & 0.11 & 10.50 & 0.001 & 0.80 & 0.37 & 1.00 & 0.32 \\
\hline Sex & 9.97 & 0.002 & 0.04 & 0.85 & 3.15 & 0.08 & 3.10 & 0.08 & 7.74 & 0.006 & 0.65 & 0.42 & 2.55 & 0.11 & 4.83 & 0.03 & 0.98 & 0.32 & 1.93 & 0.17 & 4.31 & 0.04 \\
\hline Premorbid IQ & 10.04 & 0.002 & 2.03 & 0.16 & 5.43 & 0.02 & 15.29 & 0.0001 & 0.51 & 0.48 & 1.27 & 0.26 & 7.25 & 0.008 & 0.19 & 0.67 & 10.64 & 0.001 & 0.79 & 0.38 & 2.54 & 0.11 \\
\hline Post-ECT HRSD & 0.43 & 0.51 & 0.00 & 0.95 & 2.38 & 0.12 & 0.95 & 0.33 & 0.01 & 0.94 & 0.03 & 0.86 & 0.99 & 0.32 & 0.24 & 0.62 & 0.31 & 0.58 & 0.16 & 0.69 & 0.35 & 0.56 \\
\hline $\begin{array}{l}\text { Days from end } \\
\text { of ECT }\end{array}$ & 20.57 & $<0.0001$ & 4.84 & 0.03 & 8.24 & 0.005 & 4.18 & 0.04 & 0.01 & 0.93 & 0.24 & 0.63 & 5.52 & 0.02 & 10.07 & 0.002 & 19.77 & $<0.0001$ & 30.40 & $<0.0001$ & 1.66 & 0.20 \\
\hline $\begin{array}{l}\text { Baseline test } \\
\text { score }\end{array}$ & 139.23 & $<0.0001$ & 9.30 & 0.003 & 34.48 & $<0.0001$ & 57.10 & $<0.0001$ & 18.22 & $<0.000 \mathrm{I}$ & 30.52 & $<0.0001$ & 127.15 & 0.0001 & 117.62 & $<0.0001$ & 60.23 & $<0.0001$ & 55.97 & $<0.0001$ & 78.59 & $<\mathbf{0 . 0 0 0 I}$ \\
\hline
\end{tabular}

Bolded $p$-values indicate statistically significant effects $(p<0.05)$.

Table 5 Results of the ANCOVAs on Neuropsychological Scores at the 6-Month Follow-Up

\begin{tabular}{|c|c|c|c|c|c|c|c|c|c|c|c|c|c|c|c|c|c|c|c|c|c|c|}
\hline \multirow[b]{2}{*}{ Variable } & \multicolumn{2}{|c|}{$\begin{array}{l}\text { MMMS } \\
N=191\end{array}$} & \multicolumn{2}{|c|}{$\begin{array}{c}\text { SRT } \\
N=152\end{array}$} & \multicolumn{2}{|c|}{$\begin{array}{c}\text { CRT } \\
N=169\end{array}$} & \multicolumn{2}{|c|}{$\begin{array}{c}\text { Stroop RT } \\
N=162\end{array}$} & \multicolumn{2}{|c|}{$\begin{array}{c}\text { Stroop effect } \\
\quad N=162\end{array}$} & \multicolumn{2}{|c|}{$\begin{array}{l}\text { CPT } d^{\prime} \\
N=153\end{array}$} & \multicolumn{2}{|c|}{$\begin{array}{c}\text { CFT copy } \\
N=148\end{array}$} & \multicolumn{2}{|c|}{$\begin{array}{l}\text { CFT reproduction } \\
\qquad N=139\end{array}$} & \multicolumn{2}{|c|}{$\begin{array}{l}\text { BSRT learn } \\
N=175\end{array}$} & \multicolumn{2}{|c|}{$\begin{array}{l}\text { BSRT delay } \\
\quad N=|7|\end{array}$} & \multicolumn{2}{|c|}{$\begin{array}{l}\text { AMI-SF } \\
N=186\end{array}$} \\
\hline & $F$ & $p$ & $\boldsymbol{F}$ & $p$ & $F$ & $p$ & $F$ & $p$ & $\boldsymbol{F}$ & $p$ & $\boldsymbol{F}$ & $p$ & $\boldsymbol{F}$ & $p$ & $\boldsymbol{F}$ & $p$ & $F$ & $p$ & $F$ & $p$ & $F$ & $p$ \\
\hline Waveform & 0.02 & 0.88 & 3.95 & 0.049 & 0.01 & 0.94 & 3.96 & 0.048 & 0.10 & 0.75 & 0.49 & 0.49 & 1.96 & 0.16 & 1.53 & 0.22 & 2.95 & 0.09 & 2.48 & 0.12 & 0.02 & 0.89 \\
\hline $\begin{array}{l}\text { Electrode } \\
\text { placement }\end{array}$ & 4.12 & 0.04 & 4.33 & 0.04 & 1.09 & 0.30 & 0.41 & 0.52 & 4.12 & 0.04 & 0.07 & 0.79 & 0.12 & 0.73 & 0.08 & 0.78 & 3.98 & 0.048 & 0.53 & 0.47 & 6.19 & 0.01 \\
\hline Electrical dosage & 0.21 & 0.65 & 0.09 & 0.77 & 0.37 & 0.54 & 2.27 & 0.13 & 0.10 & 0.75 & 3.33 & 0.07 & 0.11 & 0.74 & 0.03 & 0.87 & 0.00 & 0.99 & 0.02 & 0.88 & 0.11 & 0.74 \\
\hline $\begin{array}{l}\text { Number of } \\
\text { treatments }\end{array}$ & 0.51 & 0.48 & 1.54 & 0.22 & 0.66 & 0.42 & 1.40 & 0.24 & 0.09 & 0.76 & 0.70 & 0.40 & 1.26 & 0.26 & 0.66 & 0.42 & 0.33 & 0.57 & 0.54 & 0.46 & 4.79 & 0.03 \\
\hline Age (years) & 5.80 & 0.02 & 13.28 & 0.0004 & 4.11 & 0.04 & 19.63 & $<0.0001$ & 2.06 & 0.15 & 5.26 & 0.02 & 0.38 & 0.54 & 3.58 & 0.06 & 18.24 & $<0.0001$ & 17.80 & $<0.0001$ & 0.24 & 0.63 \\
\hline Sex & 0.85 & 0.36 & 1.41 & 0.24 & 0.20 & 0.66 & 0.03 & 0.87 & 8.22 & 0.005 & 1.94 & 0.17 & 0.03 & 0.87 & 0.02 & 0.90 & 4.74 & 0.03 & 5.35 & 0.02 & 4.41 & 0.04 \\
\hline Premorbid IQ & 37.07 & $<\mathbf{0 . 0 0 0 1}$ & 1.01 & 0.32 & 0.00 & 0.95 & 3.62 & 0.06 & 1.91 & 0.17 & 5.74 & 0.02 & 2.83 & 0.10 & 5.06 & 0.03 & 6.21 & 0.01 & 8.69 & 0.004 & 4.12 & 0.04 \\
\hline $\begin{array}{l}\text { HRSD } 6 \text { months } \\
\text { follow-up }\end{array}$ & 4.36 & 0.04 & 0.01 & 0.94 & 1.28 & 0.26 & 0.03 & 0.86 & 0.34 & 0.56 & 1.37 & 0.24 & 0.16 & 0.69 & 0.46 & 0.50 & 1.39 & 0.24 & 7.91 & 0.006 & 3.82 & 0.05 \\
\hline $\begin{array}{l}\text { ECT during } \\
\text { follow-up }\end{array}$ & 0.08 & 0.77 & 0.44 & 0.51 & 4.52 & 0.04 & 1.66 & 0.20 & 0.24 & 0.62 & 0.10 & 0.75 & 1.18 & 0.28 & 1.11 & 0.29 & 1.83 & 0.18 & 0.45 & 0.50 & 1.42 & 0.24 \\
\hline Baseline test score & 69.03 & $<\mathbf{0 . 0 0 0 1}$ & 35.57 & $<0.0001$ & 9.22 & 0.003 & 31.14 & $<0.0001$ & 19.14 & $<0.0001$ & 43.83 & $<0.0001$ & 73.30 & $<\mathbf{0 . 0 0 0 1}$ & 52.42 & $<0.0001$ & 77.21 & $<0.0001$ & 96.19 & $<0.0001$ & 109.20 & $<0.0001$ \\
\hline
\end{tabular}


amnesia on the AMI-SF. In the logistic regression analysis, number of BL ECT treatments was the only treatment variable that significantly predicted membership in this subgroup, $\chi^{2}(1,296)=14.7, p=0.0001$. There was also a gender difference, $\chi^{2}(1,296)=5.8, p<0.02$, with a greater preponderance of women (81.6\%) compared to men $(18.4 \%)$ in the persistent deficit group.

The analyses of study site effects were repeated now including stimulus waveform and number of treatments with each electrode placement as independent variables. The site effects were no longer significant, with the exception of mMMS scores at the 6-month follow-up. Therefore, the site differences in short- and long-term cognitive outcomes were largely attributable to variation in the type of electrical waveform and electrode placement used in ECT administration.

As seen in Tables 3 and 4, several of the covariates had powerful relations with cognitive performance at the postECT and 6-month follow-up time points. For every measure and at both time points, baseline scores had strong relationships with subsequent assessments, indicating strong reliability. For eight of the 11 post-ECT measures, cognitive performance was positively related to the number of days that elapsed from the end of ECT until the cognitive assessment. It is noteworthy that this effect did not occur with the AMI-SF, which assessed retrograde amnesia, the deficit thought to be most persistent. Two patient characteristics, age and the estimate of premorbid IQ, had frequent and strong relationships with cognitive outcomes, especially at the post-ECT assessment. In each instance, older patients and those with lower estimated intellectual function had more severe deficits. The gender differences, including the AMI-SF scores at the two time points, reflected greater deficits in women than men, and women were disproportionately represented in the group with marked and persistent impairment on the AMI-SF. Women have a substantially lower seizure threshold than men (Sackeim et al, 1987) and electrical dosage was not adjusted in most cases relative to the individual patient's seizure threshold. This pattern of gender differences might reflect the fact that electrical dosage was more markedly suprathreshold in women. Severity of depressive symptoms showed little relationship with the cognitive measures. At the post-ECT time point, none of the 11 measures were related to concurrent HRSD scores (Table 4). Findings were also negative for eight of the 11 measures at the 6-month follow-up. At this time point, lesser severity of depressive symptoms was associated with superior mMMS, delayed BSRT, and AMI-SF scores.

\section{DISCUSSION}

This was the first large-scale, prospective study of objective cognitive outcomes of patients treated with ECT. The seven hospitals differed in the magnitude of deficits at the postECT assessment (Figure 2), with significant differences in seven of the 11 cognitive measures. At the 6-month time point, differences among the hospitals persisted for the measure of global cognitive status (mMMS) and the primary outcome measure that assessed retrograde amnesia for autobiographical events (AMI-SF). In turn, these differences among the hospitals were largely attributable to differences in ECT technique. The use of sine wave stimulation and the BL electrode placement were both associated with greater short- and long-term deficits. In particular, sine wave stimulation had a marked effect on psychomotor response speed. Patients who received this form of stimulation were slowed at the 6-month assessment relative to patients treated with brief pulse stimulation on two of the three RT measures. In contrast, the long-term effects owing to electrode placement were expressed in the magnitude of retrograde amnesia. At both the short- and long-term time points, patients treated with BL ECT had greater amnesia for autobiographical events, and the extent of this amnesia was directly related to the number of BL ECT treatments received.

The demonstration of differences in the long-term cognitive outcomes as a function of hospital setting and treatment technique supports the conclusion that some forms of ECT have persistent long-term effects on cognitive performance. However, the findings do not indicate that the treatments with more benign outcomes are free of long-term effects. It is noteworthy, for example, that most cognitive parameters were substantially improved at 6-month follow-up relative to pre-ECT baseline, presumably because of the negative impact of the depressed state on baseline performance. Without evaluating a comparable group that did not receive ECT, it cannot be concluded, however, that the extent of improvement in any group returned to premorbid levels.

The finding that sine wave stimulation resulted in slowed RT could have reflected a speed/accuracy trade off, with patients receiving sine wave stimulation sacrificing response speed for accuracy. However, the sine wave and brief pulse groups did not differ in accuracy on any of the RT tasks where accuracy could be measured (CRT and Stroop). The fact that relative RT deficits were observed at the 6-month follow-up indicates a persistent change in the speed of information processing, motor initiation, or response execution. Randomized controlled studies have not found an advantage for sine wave stimulation with respect to efficacy (Andrade et al, 1988; Carney and Sheffield, 1974; Scott et al, 1992; Valentine et al, 1968; Weiner et al, 1986), and the American Psychiatric Association (2001) indicated that there is no justification for its continued use. The findings here raise the concern that this form of stimulation has deleterious long-term effects on elemental aspects of motor performance or information processing.

BL ECT results in broader and more severe short-term cognitive effects than RUL ECT, particularly with respect to retrograde amnesia. With respect to the AMI-SF scores, BL ECT resulted in greater retrograde amnesia than the other electrode placements and, even at the 6-month time point, this effect was linearly related to the number of $\mathrm{BL}$ treatments administered during the acute ECT course. The average decrement in AMI-SF scores in patients treated exclusively with BL ECT was 3.4 and 2.8 times the amount of forgetting seen in the healthy comparison groups at the post-ECT and 6-month time points, respectively, suggesting that the deficits were substantial. Furthermore, of a variety of treatment technique and patient characteristic variables, only receipt of $\mathrm{BL}$ treatment distinguished the group with marked and persistent retrograde amnesia. For decades, BL 
ECT represented the gold standard with respect to ECT efficacy, and the equivalence of RUL ECT was uncertain (Abrams, 1986). Based on accumulating evidence that the efficacy of RUL ECT is strongly influenced by dosage relative to seizure threshold, highly effective forms of RUL ECT are available (McCall et al, 2000; Sackeim et al, 2000). Indeed, recent work suggests that high dosage RUL ECT delivered with an ultrabrief stimulus maintains efficacy and results in minimal retrograde amnesia even in the period immediately following the ECT course (Sackeim, 2004b). Consequently, there appears to be little justification for the continued first-line use of BL ECT in the treatment of major depression.

Although there is a large literature on patient characteristics that predict ECT clinical outcome, little is known about the individual difference factors related to cognitive outcomes (Sobin et al, 1995). Age and premorbid estimate of IQ showed robust associations, especially at the post-ECT time point. In line with prior reports (Sackeim, 2004a), advancing age was associated with greater deficits. The findings regarding premorbid intelligence are novel. This pattern suggests that individuals with greater premorbid abilities can better compensate for the impact of ECT on cognitive functions (Stern, 2002; Stern et al, 1994).

Among the limitations of this study is the fact that differences among patients in the treatment received were not randomized, but determined by the usual practices of the setting in which they were treated and other uncontrolled factors. Thus, in theory it is possible that the associations in this observational study between cognitive outcomes and site and treatment technique factors were due to the effects of other unmeasured variables that covaried with the settings and forms of ECT administration. This concern is mitigated by three considerations. First, the findings were consistent with the results of many randomized controlled trials demonstrating that short-term cognitive outcomes are negatively impacted by receipt of sine wave stimulation or use of the BL electrode placement. The long-term effects observed in this study reflect a lack of resolution of specific deficits observed in the immediate post-ECT time period (eg retrograde amnesia). Second, there was evidence that the number of treatments administered, an essential characteristic of dosage, linearly covaried with the extent of long-term retrograde amnesia for autobiographical information for patients treated with BL ECT, but not for patients treated with RUL ECT. This provided internal support for the claim that choice of electrode placement is critical in determining the severity of long-term deficits. Finally, there was considerable variability within some sites in ECT technique, such as choice of waveform and electrode placement. Site differences in cognitive outcomes dissipated when controlling for treatment technique factors. Regardless, this study provides the first evidence in a large, prospective sample that adverse cognitive effects can persist for an extended period, and that they characterize routine treatment with ECT in community settings.

\section{ACKNOWLEDGEMENTS}

This work was supported in part by Grants R01 MH59069, R01 MH35636, R01 MH61609, and R01 MH05148 from the
National Institute of Mental Health, Bethesda, MD, USA. We thank Dr Bernard Lerer for his comments on this work, and the staff at the seven hospitals who facilitated the conduct of this study.

\section{REFERENCES}

Abrams R (1986). Is unilateral electroconvulsive therapy really the treatment of choice in endogenous depression? Ann NY Acad Sci 462: 50-55.

Abrams R (2002). Electroconvulsive Therapy. Oxford University Press: New York.

American Psychiatric Association (2001). The Practice of ECT: Recommendations for Treatment, Training and Privileging, 2nd edn. American Psychiatric Press: Washington, DC.

Andrade C, Gangadhar BN, Subbakrishna DK, Channabasavanna SM, Pradhan N (1988). A double-blind comparison of sinusoidal wave and brief-pulse electroconvulsive therapy in endogenous depression. Convulsive Ther 4: 297-305.

Ballard JC (1997). Computerized assessment of sustained attention: a review of factors affecting vigilance performance. J Clin Exp Neuropsychol 18: 843-863.

Benton AL (1977). Interactive effects of age and brain disease on reaction time. Arch Neurol 34: 369-370.

Benton AL, Blackburn HL (1957). Practice effects in reaction-time tasks in brain-injured patients. J Abnorm Soc Psychol 54: 109-113.

Breggin PR (1986). Neuropathology and cognitive dysfunction from ECT. Psychopharm Bull 22: 476-479.

Buschke H (1973). Selective reminding for analysis of memory and learning. J Verbal Learning Verbal Behav 12: 543-550.

Calev A, Gaudino EA, Squires NK, Zervas IM, Fink M (1995). ECT and non-memory cognition: a review. Br J Clin Psychol 34(Part 4): 505-515.

Carney M, Sheffield B (1974). The effects of pulse ECT in neurotic and endogenous depression. Br J Psychiatry 125: 91-94.

Cornblatt BA, Lenzenweger MJ, Erlenmeyer-Kimling L (1984). The continuous performance test, identical pairs version: Contrasting attentional profiles in schizophrenic and depressed patients. J Psychiatr Res 29: 66-85.

Donahue AB (2000). Electroconvulsive therapy and memory loss: a personal journey. J ECT 16: 133-143.

Farah A, McCall WV (1993). Electroconvulsive therapy stimulus dosing: a survey of contemporary practices. Convulsive Ther 9: 90-94.

Fink M (2004). Electroshock: Healing Mental Illness. Oxford University Press: New York.

First MB, Spitzer RL, Gibbon M, Williams JBW (1996a). Structured Clinical Interview for Axis I DSM-IV Disorders-Patient Edition (with Psychotic Screen) (SCID-I/P). Biometrics Research Department, New York State Psychiatric Institute: New York.

First MB, Spitzer RL, Gibbon M, Williams JBW, Benjamin L (1996b). Structured Clinical Interview for DSM-IV Axis II Personality Disorders (SCID-II). Biometrics Research Department, New York State Psychiatric Institute: New York.

Folstein MF, Folstein SE, McHugh PR (1975). Mini-mental state. J Psychiatr Res 12: 189-198.

Hamilton M (1967). Development of a rating scale for primary depressive illness. Br J Soc Clin Psychol 6: 278-296.

Hannay HJ, Levin HS (1985). Selective reminding test: an examination of the equivalence of four forms. J Clin Exp Neuropsychol 7: 251-263.

Johnstone B, Callahan CD, Kapila CJ, Bouman DE (1996). The comparability of the WRAT-R reading test and NAART as estimates of premorbid intelligence in neurologically impaired patients. Arch Clin Neuropsychology 11: 513-519. 
Lancaster NP, Steinert RR, Frost I (1958). Unilateral electroconvulsive therapy. J Ment Sci 104: 221-227.

Lisanby SH, Maddox JH, Prudic J, Devanand DP, Sackeim HA (2000). The effects of electroconvulsive therapy on memory of autobiographical and public events. Arch Gen Psychiatry 57: $581-590$.

MacLeod CM (1991). Half a century of research on the Stoop effect: an integrative review. Psychol Bull 109: 163-203.

McCall WV, Reboussin DM, Weiner RD, Sackeim HA (2000). Titrated moderately suprathreshold vs fixed high-dose right unilateral electroconvulsive therapy: acute antidepressant and cognitive effects. Arch Gen Psychiatry 57: 438-444.

McElhiney M, Moody B, Sackeim H (1997). The Autobiographical Memory Interview-Short Form. New York State Psychiatric Institute: New York.

McElhiney MC, Moody BJ, Steif BL, Prudic J, Devanand DP, Nobler MS et al (1995). Autobiographical memory and mood: effects of electroconvulsive therapy. Neuropsychology 9: 501-517.

Miller MD, Paradis CF, Houck PR, Mazumdar S, Stack J, Rifai AH et al (1992). Rating chronic medical illness burden in geropsychiatric practice and research: application of the Cumulative Illness Rating Scale (CIRS). Psychiatry Res 41: 237-248.

Ottosson J-O (1960). Experimental studies of the mode of action of electroconvulsive therapy. Acta Psychiatr Scand (Suppl) 145: $1-141$.

Prudic J, Olfson M, Marcus SC, Fuller RB, Sackeim HA (2004). Effectiveness of electroconvulsive therapy in community settings. Biol Psychiatry 55: 301-312.

Prudic J, Olfson M, Sackeim HA (2001). Electro-convulsive therapy practices in the community. Psychol Med 31: 929-934.

Rey A (1941). L'examen psychologique dans les cas d'encephalopathie traumatique. Arch Psychol 28: 286-340.

Sackeim HA (1992). The cognitive effects of electroconvulsive therapy. In: Moos WH, Gamzu ER, Thal LJ (eds). Cognitive Disorders: Pathophysiology and Treatment. Marcel Dekker: New York. pp 183-228.

Sackeim HA (2000). Memory and ECT: from polarization to reconciliation. J ECT 16: 87-96.

Sackeim HA (2004a). Electroconvulsive therapy in late-life depression. In: Roose SP, Sackeim HA (eds). Late-Life Depression. Oxford University Press: New York. pp 241-278.

Sackeim HA (2004b). The convulsant and anticonvulsant properties of electroconvulsive therapy: towards a focal form of brain stimulation. Clin Neurosci Rev 4: 39-57.

Sackeim HA, Decina P, Prohovnik I, Malitz S (1987). Seizure threshold in electroconvulsive therapy. Effects of sex, age, electrode placement, and number of treatments. Arch Gen Psychiatry 44: $355-360$.

Sackeim HA, Freeman J, McElhiney M, Coleman E, Prudic J, Devanand DP (1992). Effects of major depression on estimates of intelligence. J Clin Exp Neuropsychol 14: 268-288.
Sackeim HA, Portnoy S, Neeley P, Steif BL, Decina P, Malitz S (1986). Cognitive consequences of low-dosage electroconvulsive therapy. Ann NY Acad Sci 462: 326-340.

Sackeim HA, Prudic J, Devanand DP, Kiersky JE, Fitzsimons L, Moody BJ et al (1993). Effects of stimulus intensity and electrode placement on the efficacy and cognitive effects of electroconvulsive therapy. $N$ Engl J Med 328: 839-846.

Sackeim HA, Prudic J, Devanand DP, Nobler MS, Lisanby SH, Peyser $S$ et al (2000). A prospective, randomized, double-blind comparison of bilateral and right unilateral electroconvulsive therapy at different stimulus intensities. Arch Gen Psychiatry 57: 425-434.

Scott AI, Rodger CR, Stocks RH, Shering AP (1992). Is old-fashioned electroconvulsive therapy more efficacious? A randomised comparative study of bilateral brief-pulse and bilateral sine-wave treatments. $B r \quad J$ Psychiatry 160: 360-364.

Sobin C, Sackeim HA, Prudic J, Devanand DP, Moody BJ, McElhiney MC (1995). Predictors of retrograde amnesia following ECT. Am J Psychiatry 152: 995-1001.

Spreen O, Strauss E (1998). A Compendium of Neuropsychological Tests: Administration, Norms, and Commentary. Oxford University Press: New York.

Squire L (1986). Memory functions as affected by electroconvulsive therapy. Ann NY Acad Sci 462: 307-314.

Sterling P (2000). ECT damage is easy to find if you look for it. Nature 403: 242.

Stern Y (2002). What is cognitive reserve? Theory and research application of the reserve concept. J Int Neuropsychol Soc 8: 448-460.

Stern Y, Gurland B, Tatemichi TK, Tang MX, Wilder D, Mayeux R (1994). Influence of education and occupation on the incidence of Alzheimer's disease. JAMA 271: 1004-1010.

Stern Y, Sano M, Pauson J, Mayeux R (1987). Modified minimental status examination: validity and reliability. Neurology 37(Suppl 1): 179.

Sternberg DE, Jarvik ME (1976). Memory function in depression: improvement with antidepressant medication. Arch Gen Psychiatry 33: 219-224.

Valentine M, Keddie K, Dunne D (1968). A comparison of techniques in electro-convulsive therapy. $\mathrm{Br} J$ Psychiatry 114: 989-996.

Weiner RD, Rogers HJ, Davidson JR, Squire LR (1986). Effects of stimulus parameters on cognitive side effects. Ann NY Acad Sci 462: 315-325.

Zakzanis KK, Leach L, Kaplan E (1998). On the nature and pattern of neurocognitive function in major depressive disorder. Neuropsychiatry Neuropsychol Behav Neurol 11: 111-119.

Zervas IM, Calev A, Jandorf L, Schwartz J, Gaudino E, Tubi N et al (1993). Age-dependent effects of electroconvulsive therapy on memory. Convulsive Ther 9: 39-42. 